\title{
Responses to a War Memorial
}

\section{Thomas J . Scheff}

Acknowledgements: I am indebted to Bob Potter for enticing me to the memorial, and for his and Mairead Donahey's advice on writing this article.

This account grows out of my attempt to come to terms with some experiences of intense emotion over the last few years. I had strong reactions to a local Iraq War Memorial, and I subsequently observed similar reactions in others. I also recall my reaction to $9 / 11$. I try to understand the meaning of these experiences in terms of social/behavioral science, and their relevance to conflict and conflict resolution. In terms of peace activism, I address the issue of existing and new rituals that might complement protest as arms of anti-war activity.

Although I had heard about a Santa Barbara war memorial early on, it was six months before I visited. Protesting the war in Iraq in marches, I was in no hurry to see the memorial, feeling that I was already paying my dues. Beyond that, I suppose, was the suspicion that the memorial had little to offer me or anyone else.

Finally I visited one Sunday morning because my friend Bob, one of the veterans tending the memorial, was pressing me. I kept putting off the visit with various excuses. If he hadn't been so insistent, I would never have visited at all.

So I headed down to the foot of the pier where the memorial is located. It stands on the beach just to the right of the path of thousands of strollers, heading out for a pleasurable time on the wharf, a tourist site. When I got to the memorial, Bob was printing nametags to add to the crosses that make up the memorial, about five hundred at the time. He copies the names and other information about U.S. military deaths for the past week in Iraq from the Internet.

The monument itself, called Arlington West after the US military cemetery in Washington, is only temporary, as per city ordinance. Early Sunday mornings the crosses, flags, and other materials are brought to the site and installed by members of the local chapter of the Veterans for Peace. A nametag is then attached to each cross. In the evening, we remove everything, leaving nothing behind.

All of the crosses, now over two thousand, have names and other facts about a US fighter who died in the current Iraq war. Over the past two years, hundreds of thousands of tourists have walked past, and many have stopped to look at this replica of 
a military cemetery, larger than a football field. Some of the strollers talk to us as we stand on the beach below the pier, handing out memorial postcards. Some also write their comments in the notebooks we have made available on the railing, along with a listing of names of the dead that we call leaves of the fallen.

The weekly installation and removal of the memorial requires considerable effort and dedication of all or part of every Sunday to unpaid labor. Some of the vets are required to spend parts of their Saturdays also. Even though they get help from volunteers and passers by, most of the work is done by about a dozen regulars. Why are they working so hard? Perhaps the vivid responses by viewers sustain the activists.

My own response on first visit was intense. When I arrived, Bob had me install some of the nametags he had just made. Crawling in the sand between the crosses, I read the names and ages of the fallen. It was their ages, mostly 18-26, that I couldn't shake off. I was upset, as if something had stuck in my craw. I felt confused, and slightly disoriented and desperate. I already knew that over five hundred US fighters had fallen. What was the matter with me?

After finishing the stack of nametags, I returned to where Bob was working. He asked if I would do more. I said "Let me take a breather; I didn't realize how young..." I couldn't finish the sentence; I was silenced by convulsive sobs. Tears streamed down my face. I couldn't fight it anymore, I just gave in. Coming unexpectedly, my cry felt like a tsunami of grief. Magically, after some fifteen minutes when I stopped crying, I felt much better. The fog and confusion had lifted.

The deep feeling of loss revealed by my fit of crying was probably the reason I had resisted visiting. I hadn't wanted to feel it. Resistance to feeling turned out to be a theme for our visitors also. In the early weeks of the effort, the veteran's group thought of the memorial as a protest against the Iraq war. They soon realized, however, that it had much more powerful effect if it was not political. What effect does it have?

\section{Responses by Visitors}

There is little or no response from the great majority driving and walking on the pier every Sunday. Most of them seem to avoid looking, or give only a sidelong glance. Others briefly read some of the signs, then continue on their way. Here they are, walking past what surely must be a big surprise, a vast cemetery on the beach directly beneath their gaze. Very few would have known that it was there. How could they not stop? This question is further discussed below.

A substantial number, however, do stop to look. Most of those who stop talk to us. Some of them, unsolicited, read or write comments in the notebooks that lay on our railing. Although only a small percentage of the passers-by, those who stop are still a large number, perhaps three or four hundred each Sunday. 
Of this group, there is no noticeable effect on a small minority. One of the things they say is to thank us for honoring our brave dead fighting for our freedom. I have learned not to argue. More rarely, I have seen no change whatsoever in persons who come down off the pier to place flowers on the nametag of a relative or friend.

I recall one extreme example. The father of a soldier who died in Iraq had come down from the pier. He asked me to help him choose a photo from a large album to put on his son's marker. There were many pictures, beginning in infancy. When we came to a photo of his son in uniform, a handsome young teenager, just before his death, I began to cry.

Father (surprised): "What's the matter?"

Me: "I was wondering if the war in Iraq is worth the death of your son."

Father: (Again surprised). "But we had to do something."

Me: "Why is that?"

Father: "9/11."

Me: "But Iraq had nothing to do with 9/11."

Father: "Well, they're all Moslems."

I was shocked. Another vet who had overheard sought to explain, but the father seemed impervious. Like many who support the war, he was locked into an us-them stance.

In the early days of the memorial, there were a substantial number of strollers who were suspicious of the memorial, or openly angry about it. Lately the number has fallen to near zero. Most of those who stop for even a short time to talk to us or write in the notebooks seem touched by the experience. Some of the excerpts from what they write in the books on the railing hint at what has happened to them.

There are many comments that indicate strong feelings. Here a few examples:

"Very emotional and touching;" "I am profoundly touched by this thoughtful display...;" "Beautiful and touching!" "Wow, I can't even express what I feel when I see this...", and many similar comments.

Some of the comments about feelings also imply a reason for them:

"Thank you for showing us what a tragedy the war is. These crosses really bring it home..." "Seeing this brings a face to war, not just headlines." "Thank you from my heart. We must remain conscious of our losses." "Thank you for being our conscience, for waking us up..." "Thank you for keep us in touch...;" and "Thank you for jarring me into reality-it's so easy to forget..." "This makes it real...." "Thank you for being a voice for conscience. [We need] reminders that the numbers are real people..."

These comments, and many others like them, suggest strong feelings are elicited by the memorial and the reason for them. Seeing and talking to those who stop gives a more detailed picture of their responses.

A few have immediate emotional reactions on their own, without any contact with us. I have seen many women, and one man, crying all alone by the rail. Last week an elderly 
visitor barely asked me one question before tears came. Obviously disturbed by her own reaction, she quickly handed me a twenty-dollar contribution and walked off in haste. When I had invited a colleague from the university, she began crying the first moment she saw the memorial, and cried for the entire two hours of her visit. Most reactions, however are somewhat delayed. Here is an example.

A young blond in a flowery dress stops to look at the crosses and the leaves of the fallen. As she surveys the memorial, the smile on her face fades. She is obviously puzzled:

Stroller: "Which war?"

Me: "Iraq." (This was until recently a common question. Perhaps she is unsure because most the vets she sees below her are obviously too old to have fought in Iraq, even in the Gulf War. They are mostly veterans of the Vietnam War, but a few, like me, the Korean War.) She scans the memorial and the leaves of the fallen again.

Stroller: "What for?"

Me: "To honor our dead."

Then she took a long hard look at the memorial. At this point emotion began to work clearly in her face: first surprise and shock, then sadness. She cries intensely with tears streaming down her face. Then she said the thought that caused surprise: "I didn't realize how many have died." I have seen similar reactions and heard similar statements many times over. Women cry at this point, and men reach into their pocket to contribute money. Although the men don't cry, I can see sadness in their face in varying degrees.

This effect was also caught by a Santa Barbara man, Richard Anderson, who took the trouble to write to the local newspaper at length about it: An excerpt from his letter of 9/13/ 04:

Walking out into the memorial for the first time, I found myself overwhelmed with grief. One thousand casualties is just a number. One thousand crosses, with names and dates, will drive you to your knees like a sledgehammer...

Notice that this testimony names a specific emotion, grief, which is very unusual. Among the hundreds of comments in our notebooks for the strollers (like the examples above), I have never seen a specific emotion named. Although I have seen some of the strollers crying while they were writing, explicit reference to crying is never made.

In our society, we usually don't talk about specific emotions and their intense effects on us, and when we do, only by implication and indirection. Anderson also seems to refer to crying ("overwhelmed by grief") but only indirectly.

Like me before I visited the memorial, Anderson's feelings about the war, and those of the others affected by the memorial, had been asleep. The memorial woke us up. Even if had just been one person, the effort would have been rewarding. Because of the 
memorial, it has struck a large number of people, perhaps thousands. It is these strong reactions, it seems to me, that sustain the veterans' willingness to labor away their Sundays.

This discussion suggests a possible answer to the question raised above: how can the majority of strollers simply walk past the memorial with only a sidelong glance? It seems likely that at some level they do understand the meaning of the memorial, intuitively, they just don't want to deal with it. In this respect, their avoidance might be a lot like my own. The difference is that unlike me, they had no friend to cajole them.

\section{Hidden Emotions and Politics}

The role of the awakening of hidden feeling in political transformation is implied in a scene in Shakespeare's Julius Caesar. Against the advice of the other conspirators, Brutus has allowed Mark Anthony, Caesar's friend, to speak at Caesar's funeral. By his artful portrayal of Caesar, he makes him live again in the minds and hearts of the listeners. Anthony is able to connect with the mob. He then rouses them to grief over Caesar's death, leading to revolt against the conspirators. The first step occurs when the mob follows Anthony's advice: "If you have tears, prepare to shed them now." The uncovering of hidden grief can lead further beyond the tears, awaking from our own passivity.

The responses of the viewers of the war memorial suggest steps toward waking. The first specific emotion that occurs in the face of the stroller is surprise. Surprise is the emotion of transition from one mood to another. In this respect, it is like the clutch in a truck for shifting gears. If a joke is to produce laughter, it must involve surprise.

The crucial moment on the pier occurs when the stroller asks about the purpose of the memorial: "What's it for?" I say "To honor our dead." I learned that any other answer, such as "To protest an unjust war," would usually give rise to a purely verbal, rather than an emotional response. The response I give serves to unite, rather than to divide us: we both want to honor our dead. We become momentarily connected in our respect for the dead.

This moment of connection seems to be important. In addition to surprise, a change in attitude usually involves feeling a secure bond with another person. I think that this is the reason that most of the intense responses I have seen have been delayed. For most people perhaps, deeply hidden feelings can be accessed only when they feel connected with another person. Being connected, rather than alone, provides the sense of security needed to feel emotions that are anticipated to be extremely painful, if not unbearable. Note that in my own first day at the memorial, described above, my own response was delayed until I spoke to Bob, my colleague.

In this moment of connectedness, no matter the political stance, one is suddenly able to feel at least some of the grief that has been covered over until now. Until this moment, one knew about the loss of lives only intellectually, without feeling it. Until one feels the 
number of dead, it is just one of literally millions of equally un-involving bits of knowledge. It is the hitherto buried emotion that gives this particular bit of knowledge its force and its true meaning.

Understanding a situation in a new way seems to require three steps: surprise, connectedness with another person, and feeling a hidden emotion. If art involves the awakening of hidden emotions, than the Iraq war memorial, like the Vietnam memorial in Washington, is a work of art.

Cindy Sheehan, the mother of a soldier who died in Iraq, was first radicalized by her visit to AW. On Mother's Day, 2004, she had come from her home in Northern California to visit the marker of her son. She told a reporter that after crying in front of her son's cross for some time: "I'm finished crying for Casey. Now I'm crying for all the other mothers." (Santa Barbara News-Press, August 15, 2005, p. A4). Her attempt to talk to Bush during his vacation in Texas has propelled her into being the most prominent activist against the war.

\section{Exploitation vs. Uncovering of Emotions}

Since my day job is to be a social scientist of conflict, I have tried to understand my personal experiences at the memorial, and those of others I observed there, in wider terms. There is beginning to be a literature on the role of emotions in starting and stopping conflict.

The present U.S. government has exploited the fear and anger elicited by the 9/11 attack. Rather than helping people do work through their fear and anger, the regime has helped the public cover them over with angry aggression directed at I raq and other purported enemies. It is a common tactic of governments to help their supporters disguise vulnerable emotions through false pride and aggression.

Yet emotions can be mobilized in the opposite way, helping rather than hindering the process of working through. One example was discussed above: the uncovering of the strollers' hidden grief in response to viewing the war memorials, perhaps a crucial step away from war or passivity.

The experience of the Chinese Communists in mobilizing the peasants for their revolution seems to support this idea. They used political theatre and other psychological means to awake the peasants from their passive stance toward their oppression. The following is a description by a Western reporter from the early days of revolutionary activity:

As the tragedy of this poor peasant's family unfolded, the women around me wept openly and unashamedly. On every side, as I turned to look, tears were coursing down their faces. No one sobbed, no one cried out, but all wept together in silence. The agony on the stage seemed to have unlocked a thousand painful memories, a bottomless reservoir of suffering that no one could 
control...As that cry carried out across the field, the women, huddled one against the other in their dark padded jackets, shuddered as if stirred by a gust of wind, and something like a sigh moved in a wave from the front to the back of the multitude...At that moment I became aware of a new quality in the reaction of the audience. Men were weeping, and I along with them. (Hinton 1997, pp. 314-15)

Mass weeping could be a necessary step toward recovery from oppression or from passivity.

The emotional approach runs counter to the rationalism of most theories of conflict. However, in world literature there is a much broader alternative to rationalism, implied in the quest for self-knowledge. Long before Freud, the Greek philosophers proposed that the goal of philosophical thinking was knowledge of the self, and by implication, that human folly is a result of lack of self-knowledge. This thread forms one of the central concerns in both ancient and modern literature. For at least three thousand years, stories, myths, fables, satires, and more recently, novels have explored the theme of the dire consequences of lack of self-knowledge.

This theme is epitomized in one of Goethe's (1789) dramas:

The gift of the great poet is to be able to voice his suffering, even when other men would be struck dumb in their agony.

Knowledge of self is not just a cognitive matter, but also an emotional one. Identifying and giving expression to one's hidden emotions may be not only the most difficult part of knowing thyself, but also the most important. Else we remain sleepers.

There may be a need for the uncovering of two other vulnerable emotions in addition to grief: shame and fear. Freud mentioned only the grief work that is necessary to work through loss. As it turns out, fear work and shame work may be just as important. 9/11 probably created as much unacknowledged fear and shame as unacknowledged grief.

Is there also need for anger work? Probably not. Psychotherapists have long known that anger is only a secondary emotion. That is, underlying most anger is what psychotherapists call "hurt." They mean that anger is used to cover up the hurt that clients want to avoid since they sense it might be unbearably painful. However, "hurt" usually turns out to be one or more of the vulnerable emotions, grief, fear, and shame. For most men, the fear component seems particularly difficult to access. For both men and women, shame also seems to be well hidden. How could steps be taken to uncover hidden vulnerable emotions in a whole society?

\section{Rituals that Allow Grief, Fear, and Shame Work?}

One step in this direction is suggested by approaches to the control of crime that involve restorative justice. These practices lead to public acknowledgment, not only that one 
was the perpetrator or victim of a crime, but also their emotions. In the community conferences that Retzinger and I witnessed in Australia, the first step was for the victim to describe their experience, and the second step, for the perpetrator to confess to his or her part in it, and to apologize (Retzinger and Scheff 1996). This process usually provided ample room for both victim and perpetrator to express strong emotions face to face. In particular, the victim usually was able to clearly voice their suffering, and the perpetrator their shame about their behavior and its consequences. By apologizing, compensating the victim for their losses, and community service, the perpetrators avoided penal sanctions.

A similar process was realized on a much vaster scale in the hearings of the Truth and Reconciliation Commission in South Africa. The perpetrators received amnesty by fully confessing their crimes. They were not required to apologize, compensate the victim, or serve the community. The victims were allowed to voice their suffering. Some part of the success of the TRC may have been due to the tradition of ubuntu in black African culture, forgiveness based on kinship of all human beings. This issue probably needs to be clarified in order to use TRC procedures in other cultures.

It is possible that a significant part of the collective rituals needed for waking from passivity involves shame work. One realm that might involve shame work is that of apology, both at the individual and collective levels. Tavuchis (1991) has shown that both levels of apology involve intricate soul searching by both parties, and precise cooperation between them. In his analysis, the underlying emotion is grief, as indicated by the formula for apology: "I'm sorry."

However, others have proposed that although grief may be involved, the primary emotion of apology is shame/embarrassment (Goffman 1971; Miller 1993). The offense that is to be apologized for is shaming to both victim and perpetrator. A successful apology, they argue, involves the expression and resolution of shame.

To make explicit the meaning of emotion work, I propose another type of ritual: an adequate apology for the part we all play in mass violence, if only by our passive acceptance of it. Since a genuine apology could touch the basic hidden emotions, it might mark the beginning of the kind of mourning needed to avoid further acting out of anger. Here is an outline for one such apologetic mantra in regard to 9/11. With its emphasis on shame and guilt, this mantra might be particularly helpful for men, since their training to be protectors would make many of us feel a sense of responsibility about $9 / 11$.

I AM TRULY SORRY THAT THE 9/11 ATTACK OCCURRED. SINCE I WAS NOT BEING VIGILANT WHEN IT HAPPENED, I FEEL PARTIALLY RESPONSIBLE FOR ALLOWING IT TO OCCUR. (Shame and Guilt)

I FEEL VIOLATED, WEAK, HELPLESS, I MPOTENT, HUMILIATED. I AM ASHAMED OF MY OWN HELPLESSNESS. I AM ASHAMED THAT I CANNOT PROTECT MY OWN PEOPLE. I AM ASHAMED THAT I LACKED THE FORESIGHT TO SEE THIS COMING. (Shame) 
I AM SAD BEYOND RECKONING AT ALL THE LOSSES THAT WE HAVE SUFFERED. I NEED TO CRY BITTER TEARS FOREVER. (Grief)

\section{AM AFRAID. I AM AFRAID TO DIE. I FEAR FOR MY LOVED ONES AND THE CITIZENS OF THIS COUNTRY AND THE WORLD. (Fear).}

I wrote this mantra after another of my own intense emotional responses. After viewing the TV showings of the destruction of the WTT all day long, I fell into a deep funk. I finally had enough sense to turn off the TV. The funk continued, however, through the night and into the next day.

As I was listening to the radio while driving to work the next day, my usual custom, I was listening to interviews with persons who had escaped from the WTT. Many of them mentioned their surprise, as they were running down the stairs at top speed, to see police and fire-fighters running up the stairs. It finally dawned on me, in my funk, that these heroes were trying to save persons who might be stuck on the high floors. With that realization, I began to cry so intensely that I had to pull over my car. When I had finished crying, I felt my normal self again.

What happened? My guess is that the grief and other emotions that had arisen from my viewing of $9 / 11$ had been blocked by shame at my own inability to help or to have foreseen the tragedy. My funk was the result of this blockage. But hearing the interviews, I identified with the heroes. I remember wondering whether I would have had the courage to do what they did. In any case, I felt enough pride to overcome the shame that was blocking my feelings. I would think that most men, not just me, would need some kind of jolt to overcome their usual shame. The mantra might function in this way.

In addition to uncovering our own emotions, a statement like the mantra might encourage world leaders to apologize to their people also. Not just Bush, Cheney, Powell, Rumsfeld and Rice, but also Osama Bin Laden, and any other leaders who are acting like gang members rather than responsible adults.

To this point, virtually all anti-war activism has been in the form of protest and argument. It now seems to me that this format is often not effective unless of massive proportions. The thesis of this essay has been that what may be needed in addition are rituals that uncover the vulnerable emotions and create secure social bonds.

There has been considerable work already done in establishing what work must be done in order to resolve the grief connected with loss. Colin Parks (1988; "unresolved grief") and Vamik Volkan (1993; "re-grief therapy") are two of the pioneers in this area. In comparison, there has been little work on the resolution of unacknowledged fear and shame. If we are to organize rituals that will help resolve conflict, we need to learn more about how to deal not only with grief, but also with fear and shame.

It seems likely that the more a person suppresses one of these emotions, the less they will be able to experience any of them. For example, those who are still suffering from their previous losses (perhaps a majority of adults in modern societies) will be unable to 
mourn, and won't tolerate mourning in others. This mechanism would create what Volkan (2004) calls the transgenerational transmission of trauma, a key feature of his explanation of continuing enmity between groups.

It is clear that the failure to mourn is not just a deficiency of individuals, but part of a society-wide pattern. I have been told by an experienced grief counselor that for most mourners, their personal network (colleagues, friends, and family) will support mourning for only a short time (Retzinger 2004). The lost of a close relationship may require many months, even years, of grief work, but most networks become intolerant after a few weeks. Since, as already indicated, successful mourning usually requires a close relationship in which one may freely confide one's thoughts and feelings, this limitation usually blocks the completion of mourning. The inability to mourn is institutionalized in modern societies, which effects, in turn, the politics of war and peace.

There is a brilliant depiction of the barrier to feeling in this excerpt from I ris Dement's song, No Time to Cry (1993):

My father died a year ago today, the rooster started crowing when they carried Dad away

There beside my mother, in the living room, I stood with my brothers and my sisters knowing Dad was gone for good

Well, I stayed at home just long enough to lay him in the ground and then I caught a plane to do a show up north in Detroit town because I'm older now and I've got no time to cry

I've got no time to look back, I 've got no time to see the pieces of my heart that have been ripped away from me and if the feeling starts to coming, I've learned to stop 'em fast 'cause I don't know, if I let them go, they might not wanna pass And there's just so many people trying to get me on the phone and there's bills to pay, and songs to play, and a house to make a home I guess I'm older now and I've got no time to cry...

The inability to mourn is institutionalized in modern societies, which effects, in turn, the politics of war and peace. Perhaps wars will continue as long as there is collective denial. Visits to memorials and the creation of new rituals might be a step away from war toward peace. 


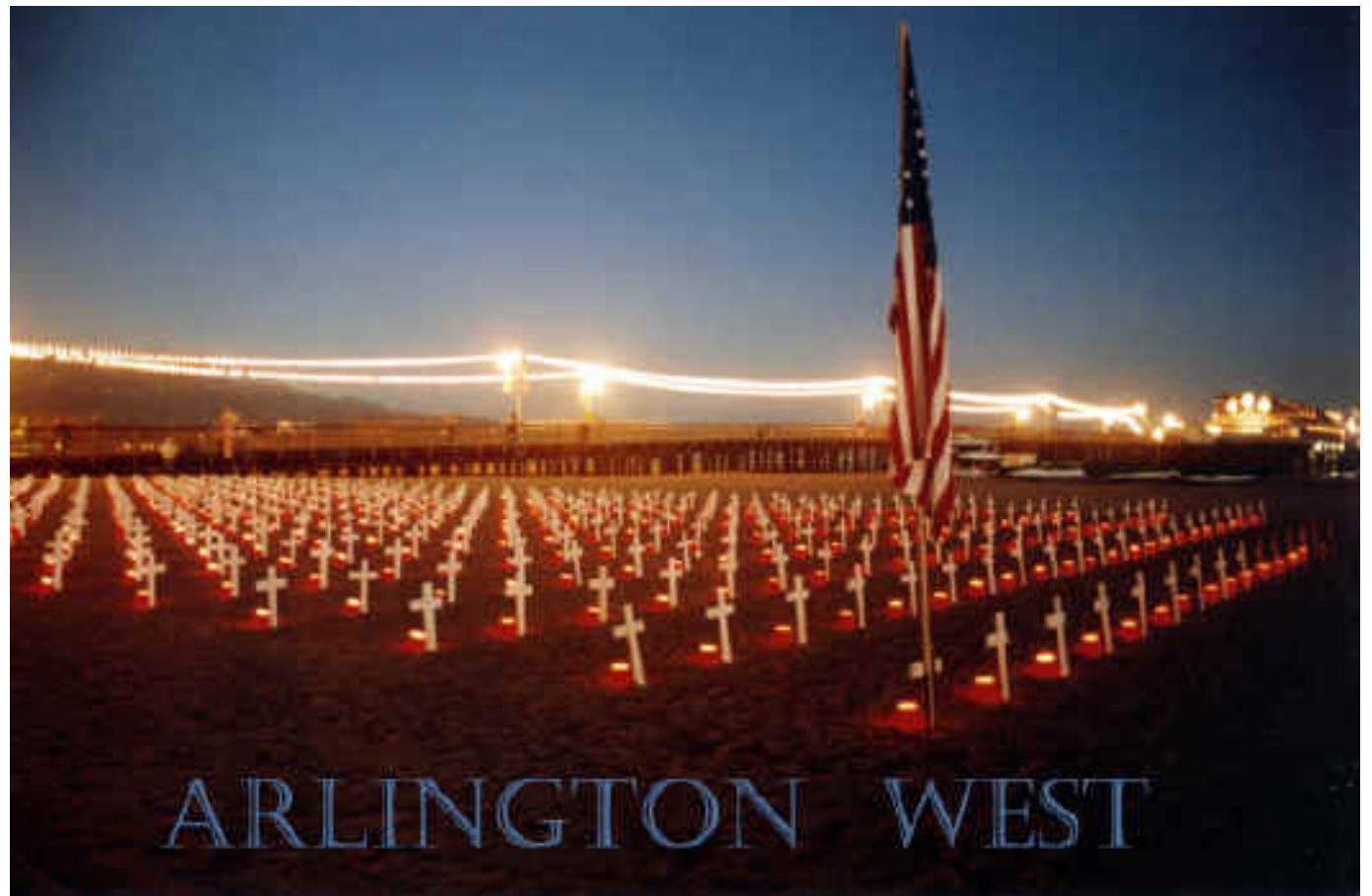

Photo: Ed Rincon

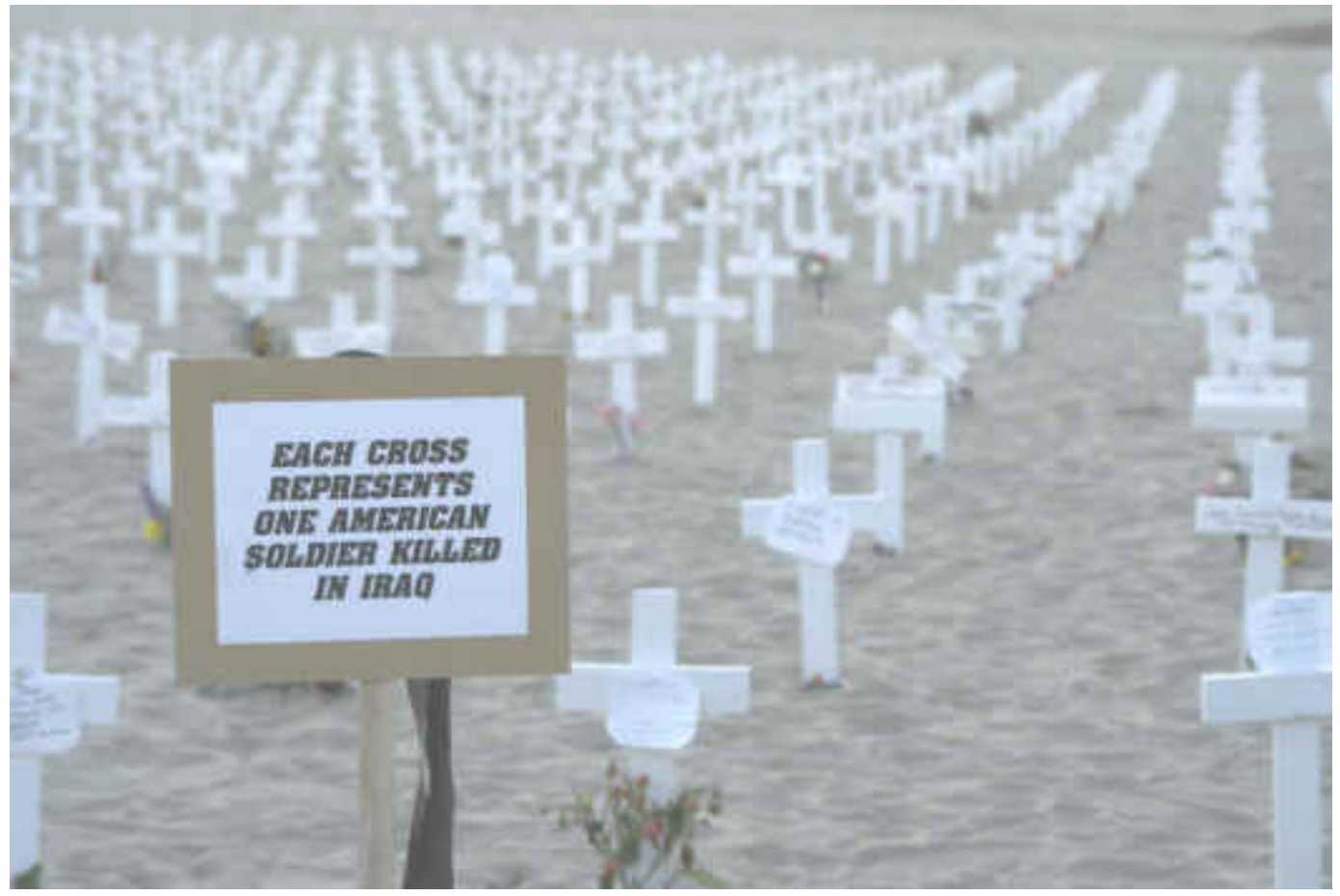



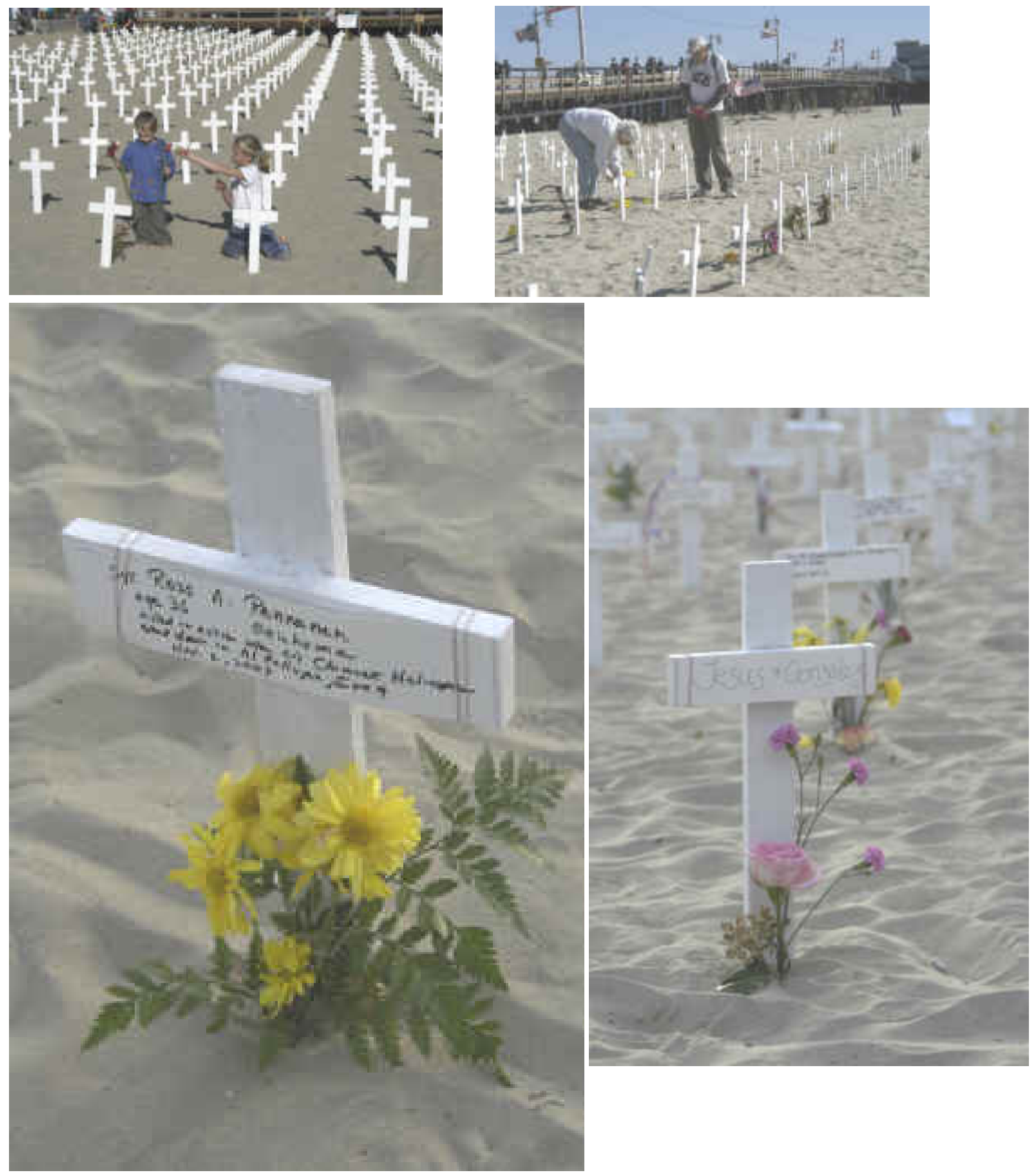

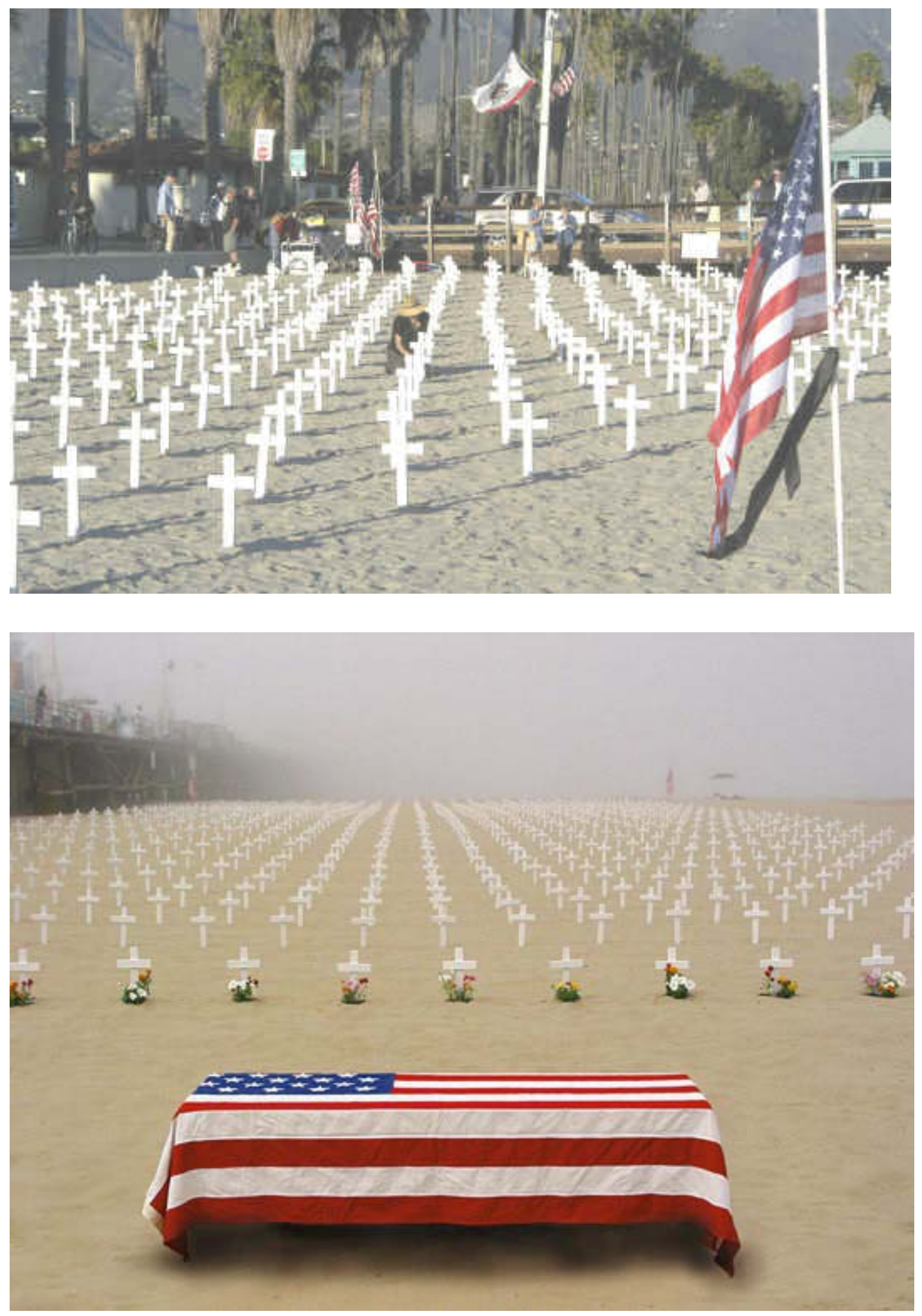


\section{References}

Goethe, Johann Wolfgang. 1789. Torquato Tasso. London: Angel Books (1985).

Goffman, Erving. 1971. Relations in Public. New York: Basic Books.

Hinton, William. 1992 . Fanshen. Berkeley: U. of California Press.

Miller, William. 1993. Humiliation. Ithaca: Cornell University Press.

Parkes, Colin. 1988. Bereavement: Studies of grief in adult life_(3rd ed.)Madison, CT: International Universities Press, Inc. (1998)

Scheff, T. J. and S. M. Retzinger 1996. Strategy for Community Conferences. in B. Galaway and J. Hudson, Editors. Restorative Justice: International Perspectives. Criminal J ustice Press.

Tavuchis, Nicholas. 1991. Mea Culpa: A Sociology of Apology and Reconciliation. Stanford: Stanford University Press.

Volkan, V. D. 2004. Blind Trust: Large Groups and Their Leaders in Times of Crisis and Terror. Charlottesville, Virginia: Pitchstone Publishing.

Volkan, Vamık D. and Zintl, Elizabeth (1993). Life After Loss: Lessons of Grief. New York, NY: Charles Scribner's Sons. (Paperback Edition, 1994).

4999 April 10, 06 pactive 